\title{
Using R, LaTeX and Wiki for an Arabic e-learning platform
}

\author{
Taleb Ahmad*
Wolfgang Härdle* \\ Taleb Ahmad*
Wolfgang Härdle* \\ Sigbert Klinke* \\ Shafeeqah Al Ahwadi**
}

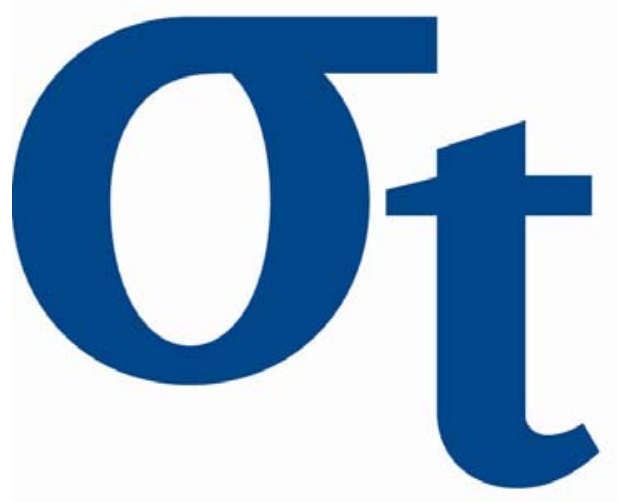

$\underline{Y}$

U

a

* Humboldt-Universität zu Berlin, Germany ** Kuwait University, Kuwait 


\title{
Using R, LaTeX and Wiki for an Arabic e-learning platform *
}

Taleb Ahmad, Wolfgang Härdle, Sigbert Klinke and Shafeeqah Al Awadhi

\author{
CASE - Center for Applied Statistics and Economics \\ Institute for statistics and Econometrics \\ Humboldt-Universität zu Berlin \\ Wirtschaftswissenschaftliche Fakultät \\ Spandauerstrasse 1, 10178 Berlin, Germany
}

June 1,2007

\begin{abstract}
E-learning plays an important role in education as it supports online education via computer networks and provides educational services by utilising information technologies. We present a case study describing the development of an Arabic language elearning course in statistics. Discussed are issues concerning e-learning in Arab countries with special focus on problems of the application of e-learning in the Arab world and the difficulties concerning the design Arabic platforms such as language problems, cultural and technical problems, especially ArabTeX works difficulty with LaTeX format. Thus Wiki is offered as a solution to such problems. Wiki supports LaTeX and other statistical programs, for instance R, and Wiki offers the solution to language problems. Details of this technology are discussed and a solution as to how this system can serve in building an Arab platform is presented.
\end{abstract}

Keywords: E-learning, MM*Stat, Wiki, ArabTeX, Statistical software

JEL Classification 121, C19

*This research was supported by the Deutsche Forschungsgemeinschaft through the SFB 649 'Economic Risk'. Corresponding author: Taleb Ahmad, CASE - Center for Applied Statistics and Economics, HumboldtUniversität zu Berlin, Spandauer Str. 1, 10178 Berlin, Germany, email: tahmad@wiwi.hu-berlin.de 


\section{Introduction}

Due to the proliferation of the Internet, e-learning has become significant within education. Universities and educational institutions have created web sites and e-learning systems. In the future e-learning is expected to provide a complement to classical learning and the elearning market is expected to become for software companies. In spite of this the e-learning market is still weak in Arab countries when compared to America and Europe. The reason why the software industry is weak in the Arab world has several reasons and will be discussed later. Our internet research shows that electronic platforms are few in Arab universities and an Arab e-learning platform in statistics could not be found. For this reason we find the creation a platform that would aid Arabic students in learning statistics highly necessary. From this perspective we are currently working on the development of an Arab e-learning platform in statistics (Arabic MM*Stat). The platform will contain the basic statistical topics, will be supported by multiple examples and the easy-of-use will be adapted for Arab students. It will be an important reference point in the study of statistics through the Internet. MM*Stat is an HTML based multimedia environment for supporting teaching and learning statistics via the internet or from a CD. The main aim is to discuss why LaTeX2HTML does not work with Arabic MM*Stat, therefore we use another technology, namely the "Wiki technology". Wiki defines as software tool for collective operation through the internet and it uses easy rules to create web pages. Despite its young age e-learning has begun spreading worldwide and in particular in western countries. Statistics show that the size of the worldwide e-learning market is estimated to be 11 billion dollars yearly, with this ratio located between $60-70 \%$ in the United States and Europe. Statistics indicate that $30 \%$ of the education was delivered electronically. There is a big gap between Europe and the United States and the Arab countries, where the size of e-learning market is around 15 million dollars yearly. Al-Reeise (2004). The reasons for this gap can be shortly summarized using the following facts:

- The diffusion of the internet services in the most Arabic countries is weak compared to other regions of the world. This is mainly due to the government monopolies over the telecommunications sector, resulting in higher prices. As a consequence only $0.5 \%$ of the internet users come from the Arab world, even though the Arab population is 5\% of the world population. 
Another example for this gap is the number of personal Computers. 20 per thousand in Arab countries compared with 200 per thousand in the developed countries. Al-Reeise (2004).

- As English is the most common language in the e-learning platforms and most Arab users have difficulties in understanding and speaking English, users do not have enough experience and ability to contact with others using English and that distances them from e-learning sources and educational courses.

- Social and cultural problems: Every language contains within the traditions and customs of the people speaking it. Restrictions are imposed by some Arab governments for internet users as it contains to opinions that violate the traditions and cultural values.

- The educational problems: A high level of illiteracy in the Arab world. 23, 21\%. See: http://www.sajed.org/news.php?ID=48.

- A limited number of specialized cadres and the scientific expertise in the area of elearning in the Arab countries.

Due to the mentioned problems the Arab countries need more time to acquire the advantage of e-learning. The dissemination of the culture of e-learning in the schools and universities needs a new generation of qualified people who can deal successfully with modern technology and the experiences of e-learning.

\section{Difficulties to design Arabic platforms}

There are many problems associated with the making of an Arabic platform, these relate to language, cultural and also technical. We summarize these issues :

Problem 1: The writing in Arabic is from right to left opposite to most other languages. Therefore all lists, paragraphs, statistical forms, tables and graphics run from right to left. In some cases however Arabic text may contain information that needs to run in the opposite direction (from left to right) like numbers and Latin texts. Any program that supports the Arabic language should provide the possibility of changing the direction when needed. 
Problem 2: There are some items related with translation, some words and scientific terms are similar in Arabic and could create a problem when translated. For example, see table 1. Arabic makes no distinction between "administration" and "management". Another example, "calculate" and "calculator" are ambiguous as well as "compute" and "computer."

\begin{tabular}{|c|c|}
\hline Arabic & English \\
\hline الدازة & Administration \\
\hline أدارة & Management \\
\hline يحسب & Calculate \\
\hline يحسب & Compute \\
\hline حاسوب & Calculator \\
\hline حانسوب & Computer \\
\hline
\end{tabular}

Table 1: Some similar words in Arabic

Problem 3: We must consider the issues relating specifically to Arabic culture. As traditions, cultural values play an important role in every society. "The cultural effects of using a different language. Each language has its own characteristics acting as a container in which morals and values are presented. It carries the culture of those people speaking it". Al-Khatib (2004).

Problem 4: Another problem is the LaTeX format. ArabTeX works difficulty with LaTeX. We aim to find a solution to this problem in our project. There was a project for Arabtex in LaTeX presented by Prof. Klaus Lagally - University Stuttgart (1993). This project was a positive step but it is not enough as the letters in Arab texts in this project were written in English and not Arabic and this project did not have the ability to produce statistics on an Arabic Web site. Figure 1 shows how to implemented ArabTeX into LaTeX in that project. 
|documentstyle[12pt,arabtex] \{article\}

|begin\{document\}

lsetarab \% choose the language conventions

|vocalize \% diacritics for short vovels on

Itranstrue $\%$ additionally svitch on the transliteration

larabtrue $\%$ print arabic text ... is on anyvay

Ispreadtrue \% spread out caption

|centerline $\{\langle$ gu, ha pa - , hindruhu $\}\}$

|begin\{arabtext\}

'at_A sadiqull 'il_A "gu, hat ya, tlubu nishu, hindrahu li-yarkabahu fI safraTill ga, 8Ira7ill pa-qlla lahu:

sarfa 'u'Iduhu 'ilayka fI al-nash'i, wa-' 'adfa'ul laka 'u"grad'all, II ta-ghla "gu, ht:

'and 'Asifull "giiddall 'annI IA 'asta, tI'u 'an 'u, haqqiga laka ra,gbataka, fa-al, himaru laysa huna al-yanma, II va-qgabla 'an yutimu "gu, hat kal hamahu

bada'a al--himlru yanhaqu fI i,s,tablihi. II

ta-ghla lahu, sadIguhu:

'innI 'asu'tu, himaraka yd "ggu, ha janhaqu, II

ta-ghla lahu "gu, hat:

.garIbull 'anruka yA , sadigi!

'a-tu, saddiqu al-, himara aa-tuka d dibunI?

lend\{arabtext\}

lend\{document\}

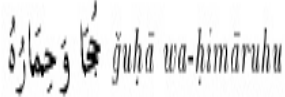

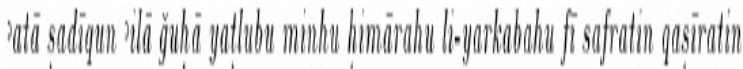

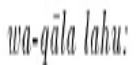

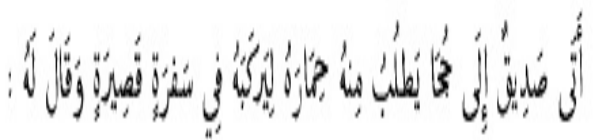

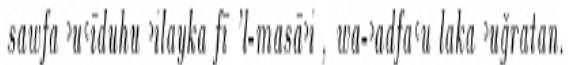

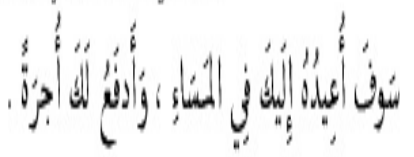

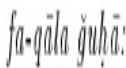

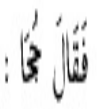

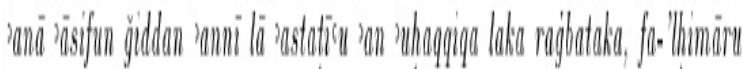

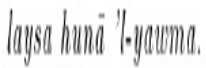

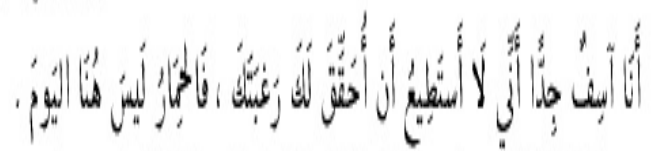

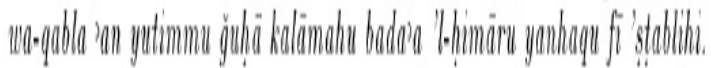

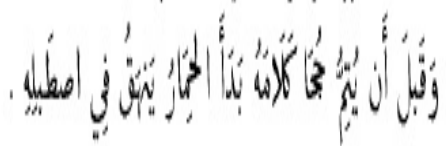

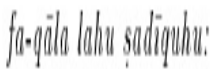

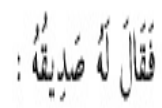

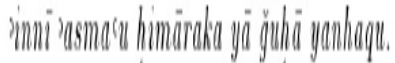

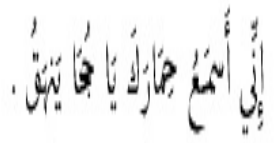

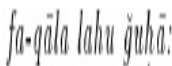

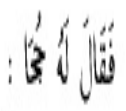

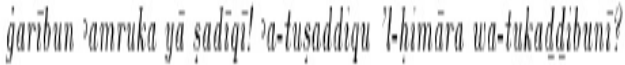

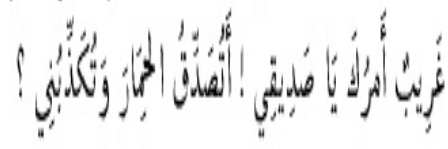

Figure 1: Left panel: Sample Arabtex input in LaTeX, right panel: Sample Arabtex output in

\section{LaTeX}


Problem 5: How to include the interactive examples in Arabic MM*Stat? These kind of examples are important, because interactive examples allow the user to practice repeatedly with various variables or data sets, and with alternate sample sizes or parameters, of the statistical methods applied. In this manner, the student obtains a better understanding of how the statistical method works. Lehmann (2004).

\section{WiKi Technology}

We propose the Wiki technology as a solution to these problems. Wiki supports the solutions for language problems, and on top of this it is an easy tool to create web page. Wiki software supports LaTeX format to writing the complex statistical forms, and we will try to integrate of LaTeX into Arabic MM*Stat. We will use R program to do the interactive examples and multiple choice question in Arabic MM*Stat, thus $\mathrm{R}$ will be integrated into Wiki.

\subsection{What is Wiki ?}

Wiki is a system that allows users to collaborate in forming the content of a web site. The first web site in wiki, "WikiWikiWeb" was designed by Ward Cunnigham and Bo Leuf in 1995. They describe the Wiki system as a simple database that can operate on the World Wide Web. The goal is to simplify the process of participation and cooperation in the development of web content with maximum flexibility. The main advantages of Wiki are that:

- Wiki simplifies the process of content editing. Each page contains a link for changing contents through an editing screen which can then be saved. The saved pages can be viewed on the web site.

- It uses simple markup to coordinate contents, and it is suitable for users with little experience with computers or web site development as no HTML language knowledge is required.

- Wiki sites keep record of the history pages and therefore makes the comparison of older and newer web pages an easy task. If a mistake is made, one can revert to the older version of the page.

- Most Wiki sites are publicly open and therefore content editing by users is open. 
- Wiki simplifies the organization of a site: Wiki sites create hypertext databases and can regulate the content in any manner desired; many of the content management systems require the planning of a classifications for of content before anything is written; in Wiki one can organize the contents by the sections or without the sections. Visitors to the web site can use the links between the pages. This flexibility is not available in the content management systems.

\subsection{Application of Wiki}

The flexibility of the Wiki concept makes it an ideal knowledge transfer tool, at universities, educational institutes, in companies and with specialized web sites." Wiki serves easily as an effective tool for communication between students and professors in the universities and for publishing articles, documents as well as lectures.” ( See: http://www.serdal.com/articles/6/). In many universities students are not required to visit lectures since lectures are written and published on the university web site. Each teacher can write his course using Wiki and offer it to his students as an useful material for the study. There are many examples of web sites dependent on Wiki as tool for the development of the contents, like Wikipedia, see the link: http://en.wikipedia.org. The Wikipedia project started 15 January 2001 and today there are more than 5.5 million articles in the encyclopedia in all languages, more than 1.5 million articles in the English encyclopedia alone. Millions of volunteers around the world modify and add to the contents daily and a new articles are created. The Arabic version of the free encyclopedia was launched in July 2003 and currently contains only 30,210 articles only as the Arab encyclopedia is in the content-building phase. There is a great potential as a tool for online collaboration in Humboldt university from Dr. Sigbert Klinke, this project was applied in the web site: http://teachwiki.wiwi.hu-berlin.de. And there is Arabic e-learning platform in Wiki. http://wiki.arabeyes.org. Arabeyes provides a good environment for discussion and exchange of experience and knowledge about the Arabic language and support it with the computer and free software, Arabeyes offers the translation for a free open-source programs. In addition there is in Arabeyes the technical dictionary that aims to translate and standardize the technical terms used in translating the software to the Arab user. Arabeyes is a solution for problem 2, see later figure 2. Wiki supports the solution for problem 1, see figures 4, 6 and 9 . 
It also supports $\operatorname{LaTeX}$ to writing the complex statistical forms into Arabic MM*Stat, a solution for problem 4 , see figure 4

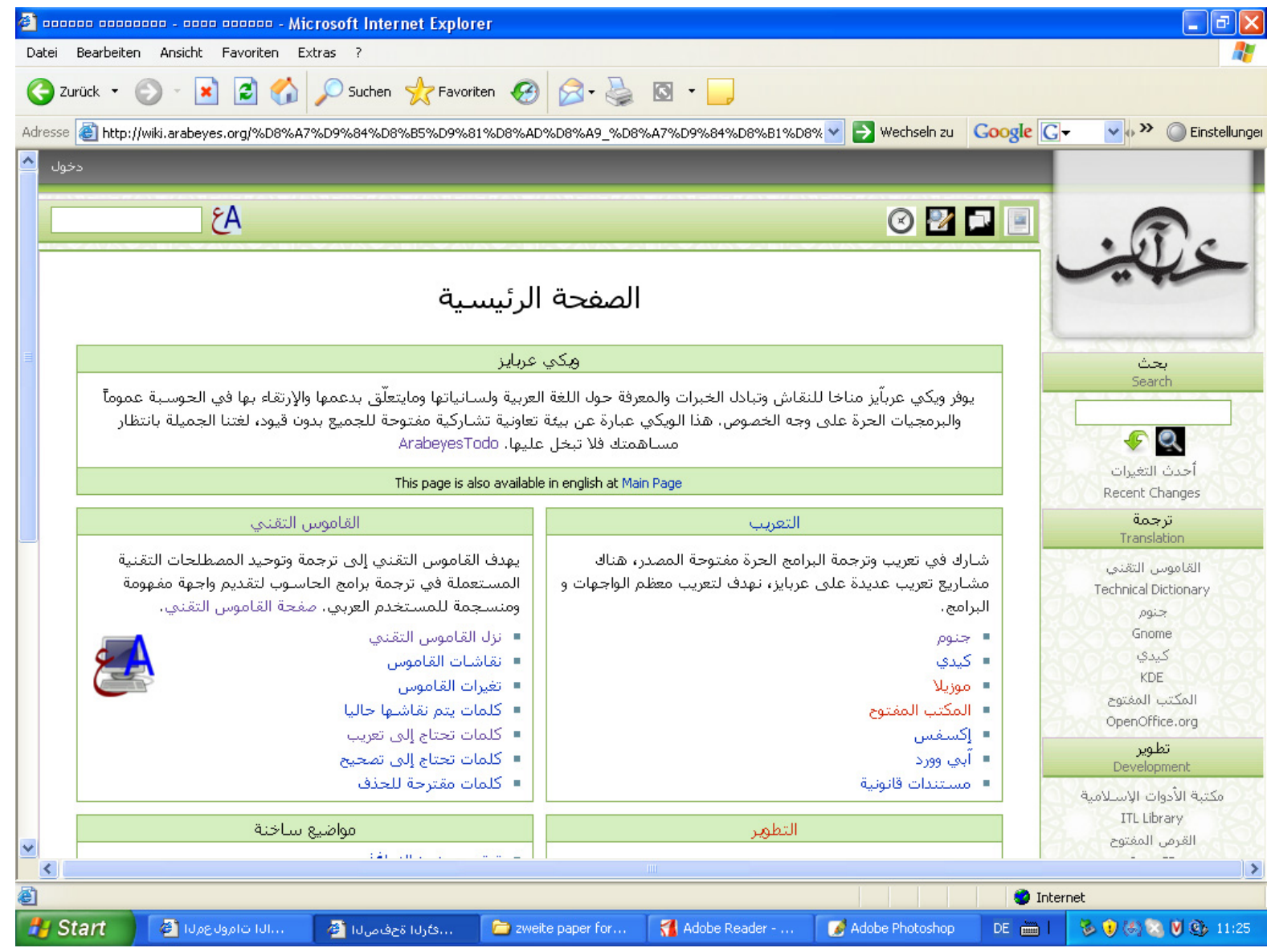

Figure 2: Graphical user interface (GUI) of Arabeyes Todo 


\section{An Arabic e-learning system}

\subsection{Description of Arabic MM*Stat}

The basic frame for this platform, the system MM*Stat was developed at the School for Business and Economics of Humboldt - Universität zu Berlin. MM*Stat is a platform for elearning statistics and it is an HTML based multimedia environment to support teaching and learning statistics via internet or $\mathrm{CD}$, see: http://www.quantlet.com/mdstat/products.html. It provides e-learning of Statistics in many languages including English, German, French, Polish, Czech, Spanish and Italian.

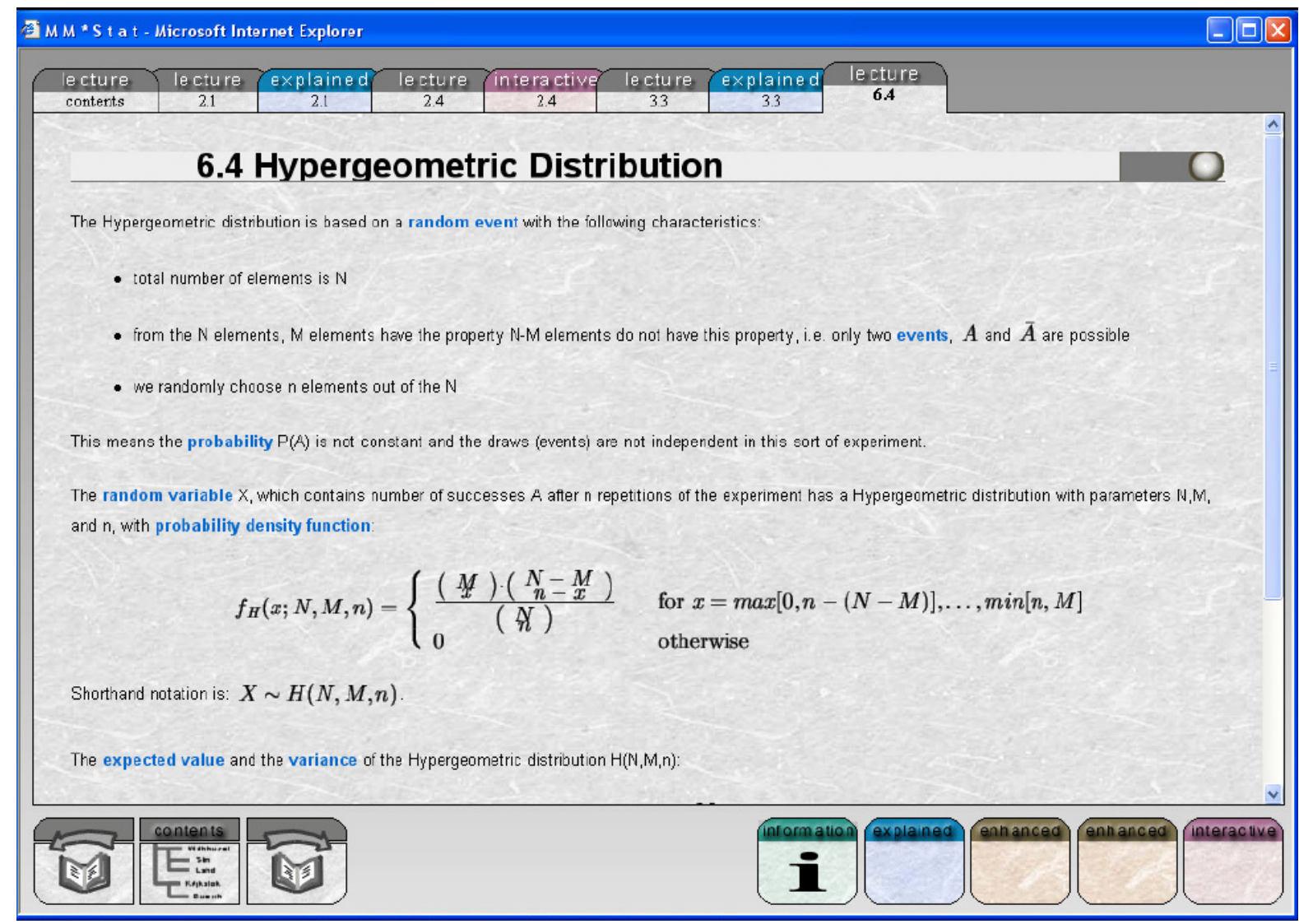

Figure 3: Standardization is via an HTML filing card system

Arabic MM*Stat is directed to students and Arab users that serve the e-learning issues in the Arab region. There are not enough e-learning platforms because there is a lack of interest 


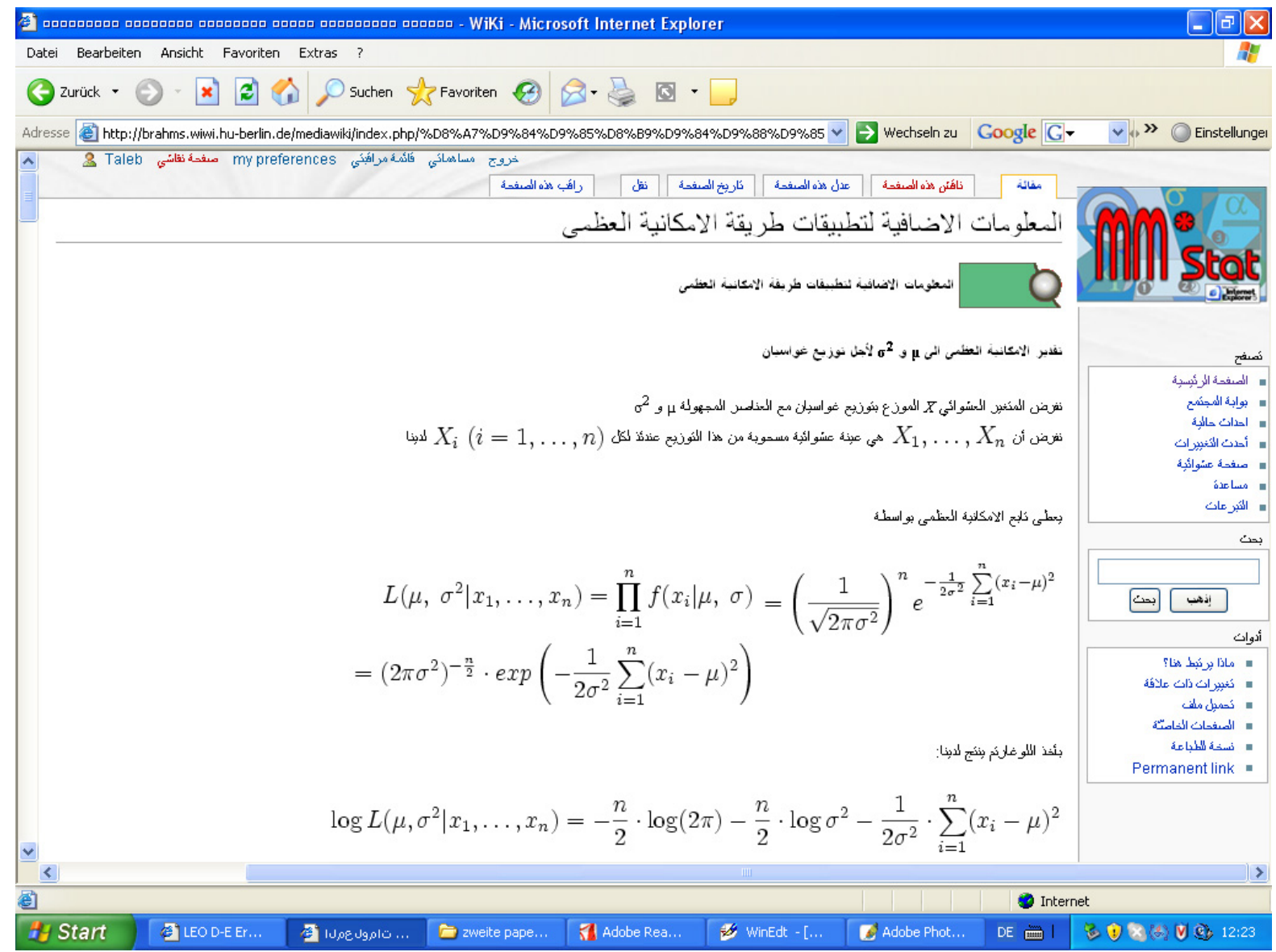

Figure 4: Graphical user interface (GUI) of Arabic MM*Stat in WiKi

in the e-learning issues within universities and Arab institutes. This platform will be the first developed platform for Arab users in statistics and it is applied in the following web page see: (http://pluto.wiwi.hu-berlin.de/mediawiki/index.php).

MM*Stat course has five components structures: The lecture, information, explained, enhanced and interactive. Each lecture gives the basic concepts of the general statistical theory, definitions, formulae as well as mathematical proofs. MM*Stat provides the students to compute distribution functions, graphics and derive results for statistical tests. The students or anyone interested in statistics can interactively learn about basic concepts of statistics at anytime and anywhere. 


\subsection{How to introduce new contents into Arabic MM*Stat?}

These principles and rules of Wiki are very important for designing Arabic MM*Stat that operates using Wiki. These principles reduce the effort and cost associated with the creation of simple web pages that works with the HTML language.

- Adding of new pages: The establishment of the pages for links existed already and sometimes refers to the pages of the articles not yet established. Before pages are established it must be confirmed that no page has been previously been created and that it is separate from the other pages.

- Editing pages: Editing and modifying pages is an easy process. Click the link "edit this page" located at the top of the page, moved this link to another page "edit page", where the contents of the page are for the adding and preview and when we finish the writing. The page must be saved and we can see all the changes made by clicking the button "show preview".

- Addition the internal and external links to Arabic MM*Stat: When we write a word or sentence between brackets, this sentence will work as an internal link in Arabic $\mathrm{MM}^{*}$ Stat and pages already existing will appear in blue. If the page does not exist, the link color will appear in red. This relates only to internal links in Wiki. However external links can also be created with ease.

- Addition variables and statistical formulas: Writing in Arabic $\mathrm{MM}^{*}$ Stat dependent basically on the mathematical and statistical formulas. All statistical formulas can be rewritten from Arabic Wikipedia. See: http://ar.wikipedia.org/wiki/.

- The creation of tables in Arabic MM*Stat: There are two ways to create tables. The first is using HTML. Formulas can be applied to the HTML environment, and the following example in figure 5 explains that. Since some users are unfamiliar with HTML or because some symbols of tables are difficult, we apply Wiki method as the figure 6 . 


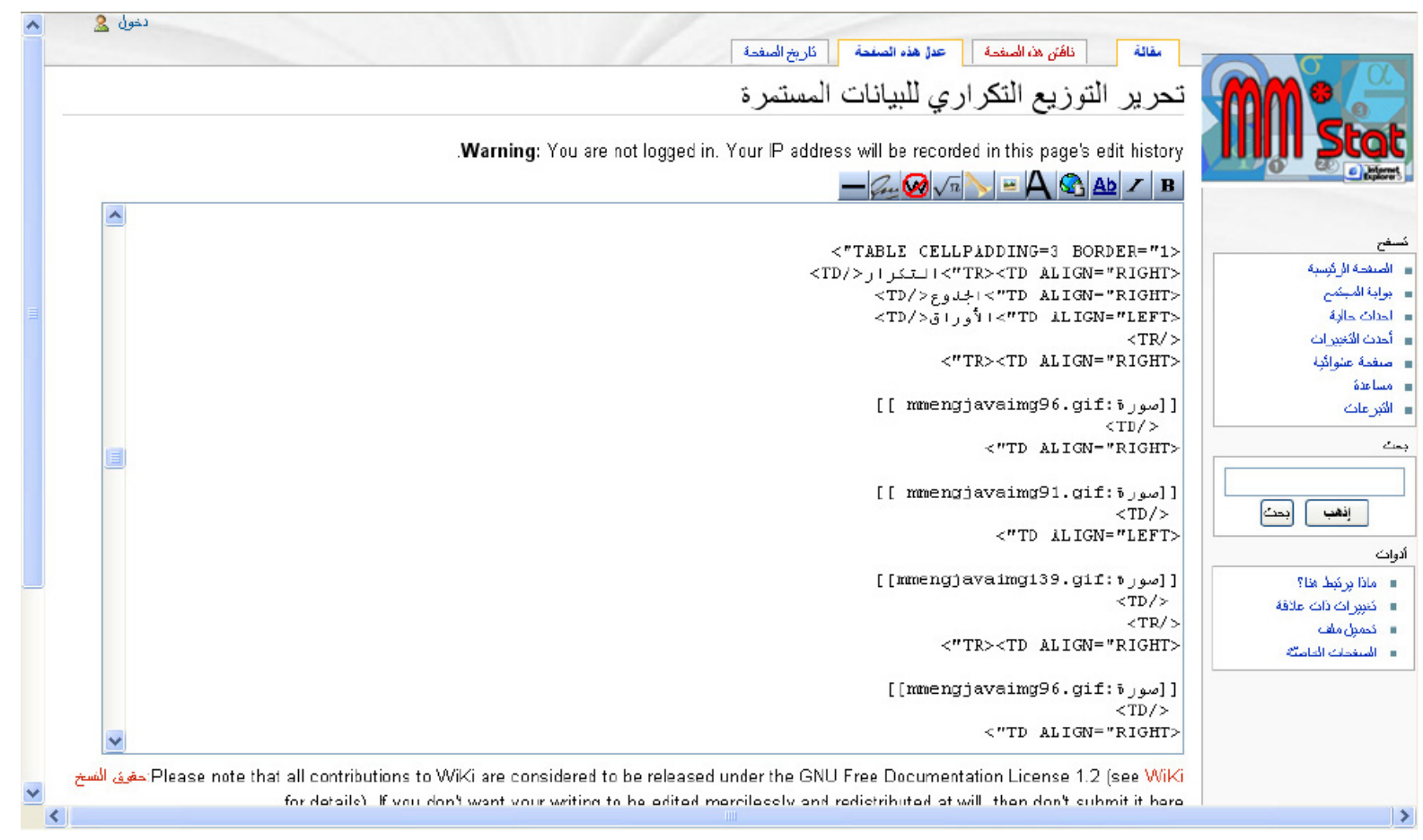

Figure 5: Edit table in Arabic MM*Stat using HTML

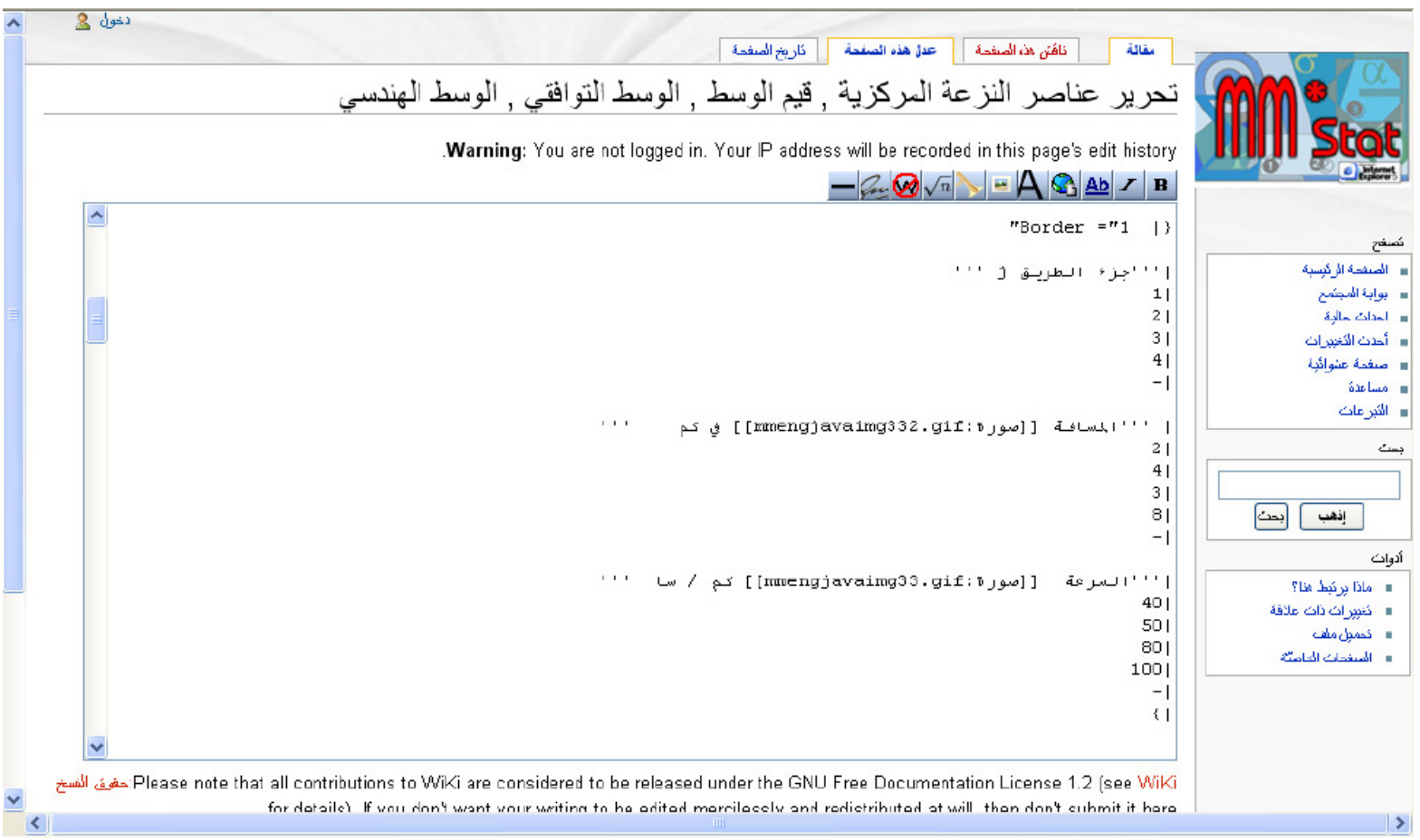

Figure 6: Edit table in Arabic MM*Stat using Wiki 
We must consider the issues relating specifically to Arabic culture. For example: Interest rates or the prohibition of alcohol. There were in $\mathrm{MM}^{*}$ Stat many examples relating to this. We must delete them from Arabic MM*Stat like figure 7 and 8 . The user can delete these examples directly during the working on Wiki. Here comes the importance of Wiki as a edit tool. It also a solution for problem 3.

\section{Explained: A Deck of Cards}

Assume you have shuffled a standard deck of 52 playing cards. You are interested in the probability of a randomly drawn card being a queen or a heart'. We are thus interested in probability of the event $(\{$ Queen $\} \cup\{$ Heart $\})$

Following Laplace's notion of probability, we proceed as follows: There are 4 queens and 13 hearts in the deck. Hence,

- $P(\{$ Queen $\})=\frac{4}{52}$

- $P(\{$ Heart $\})=\frac{13}{52}$

But there is also one card which is both a queen and a heart. As this card is included in both counts, we would overstate the probability of either queen or heart appearing if we simply added both probabilities. In fact, the addition rule of probability requires one to deduct the probability of this joint event:

$$
P(A \cup B)=P(A)+P(B)-P(A \cap B)
$$

Figure 7: An example for deck of cards

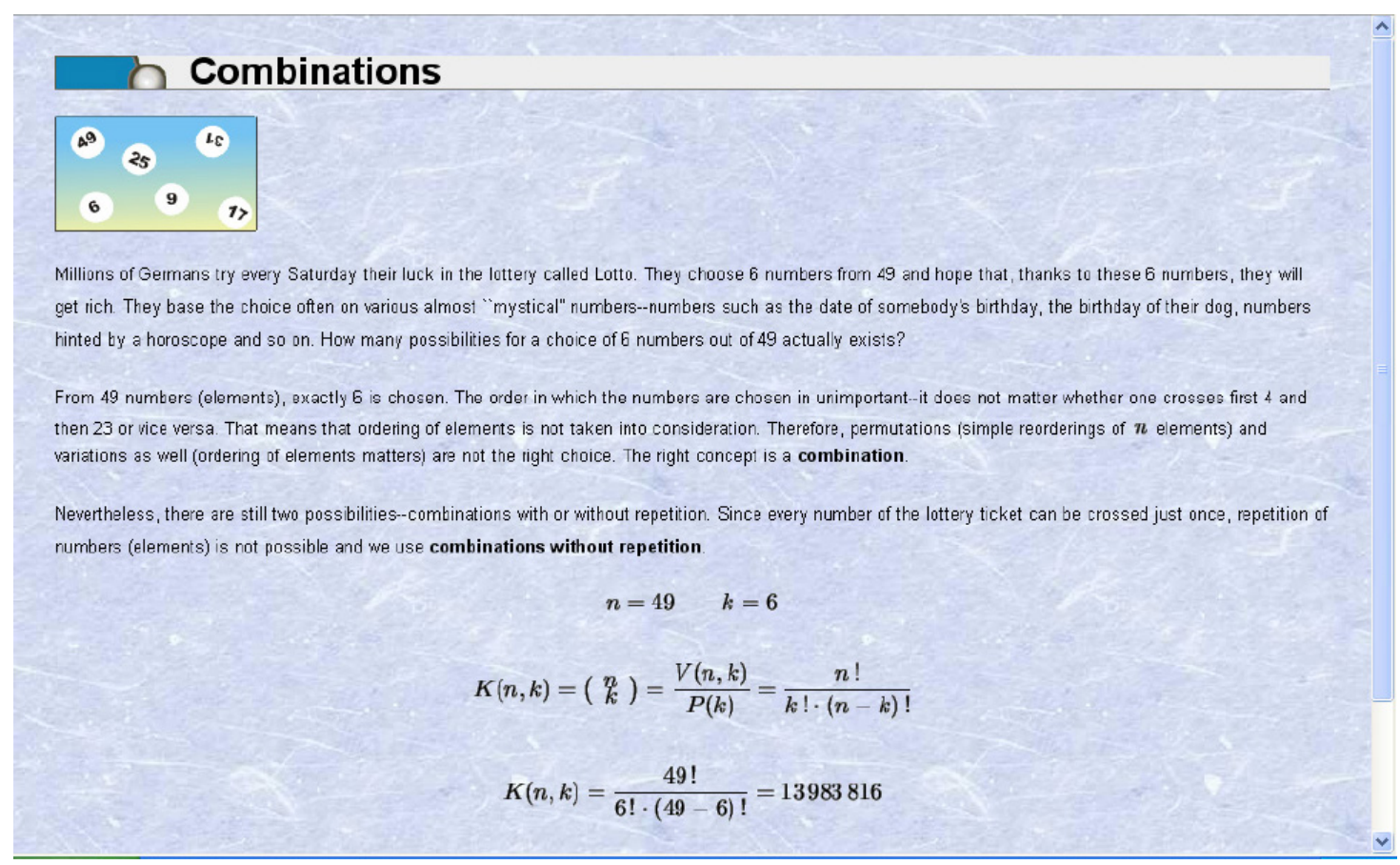

Figure 8: An example for lotto 


\section{Integrate R program into Wiki}

$\mathrm{R}$ is a language and environment for statistical computing and graphics. It was originally created by Ross Ihaka and Robert Gentleman at the University of Auckland, New Zealand, and is now developed by the $\mathrm{R}$ Development Core Team. R provides a wide variety of statistical (linear and nonlinear modelling, classical statistical tests, time-series analysis, classification, clustering, ...) and graphical techniques, and is highly extensible (see: http://www.r-project.org/about.html). Arabic MM*Stat provides $\mathrm{R}$ program which can be incorporated with the courses notes. The Mediawiki is the software behind the Wikipedia. This extension allows to run R programs within the Mediawiki and to display graphics, HTML output and the interactive examples in the Arabic MM*Stat. As a solution for problem 5. These interactive examples enable the students and learner to apply the statistics distributions and the probability tables via the internet. (For examples, see figure 9). This example explains how to apply the hypergeometric distribution for various values. Other example (see figure 10) shows the graphic for the binomial distribution and you can get other graphic when you input other values. There are in Arabic MM*Stat other examples for other distributions like normal, poisson and exponential distribution. 


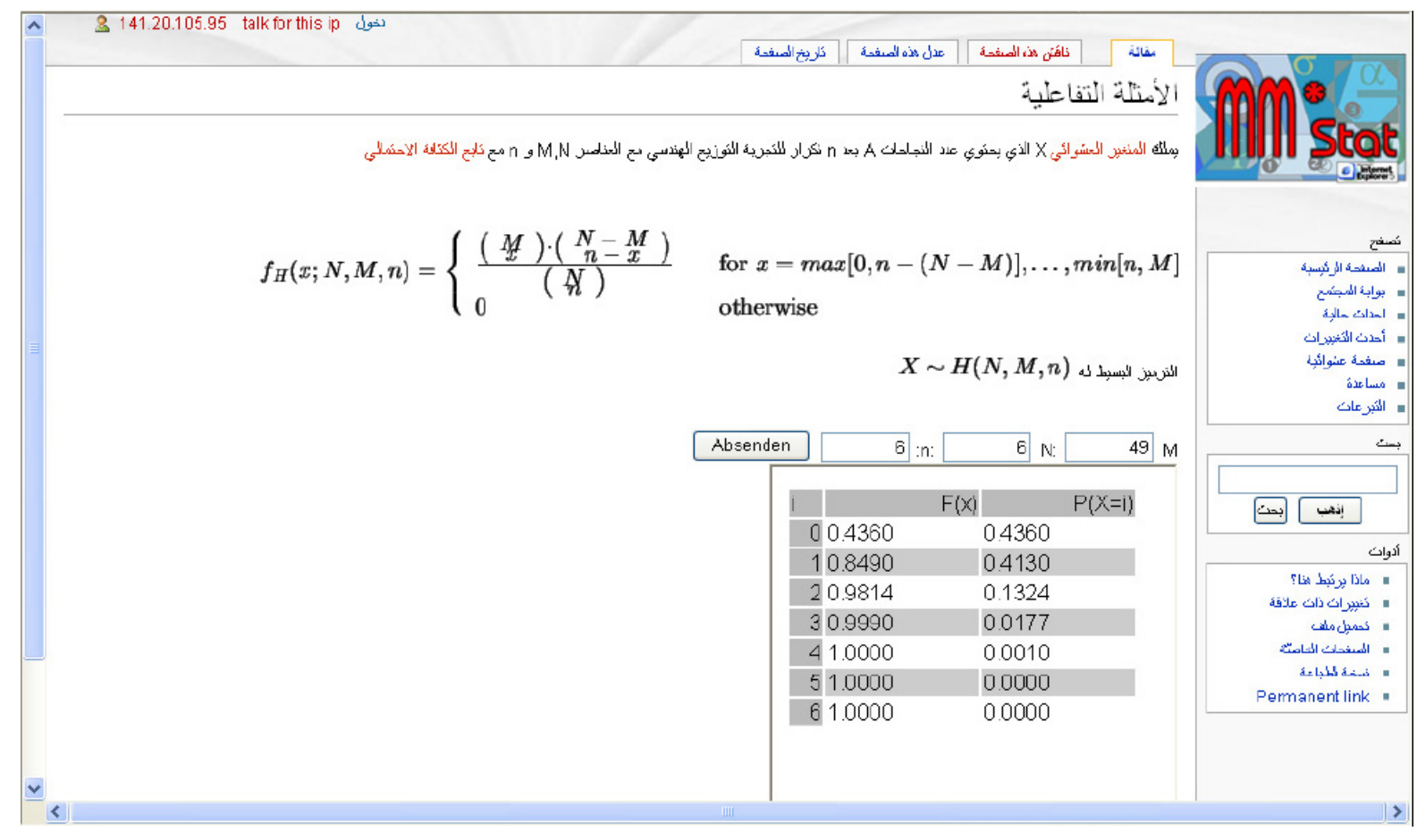

Figure 9: The interactive example for hypergeometric distribution.

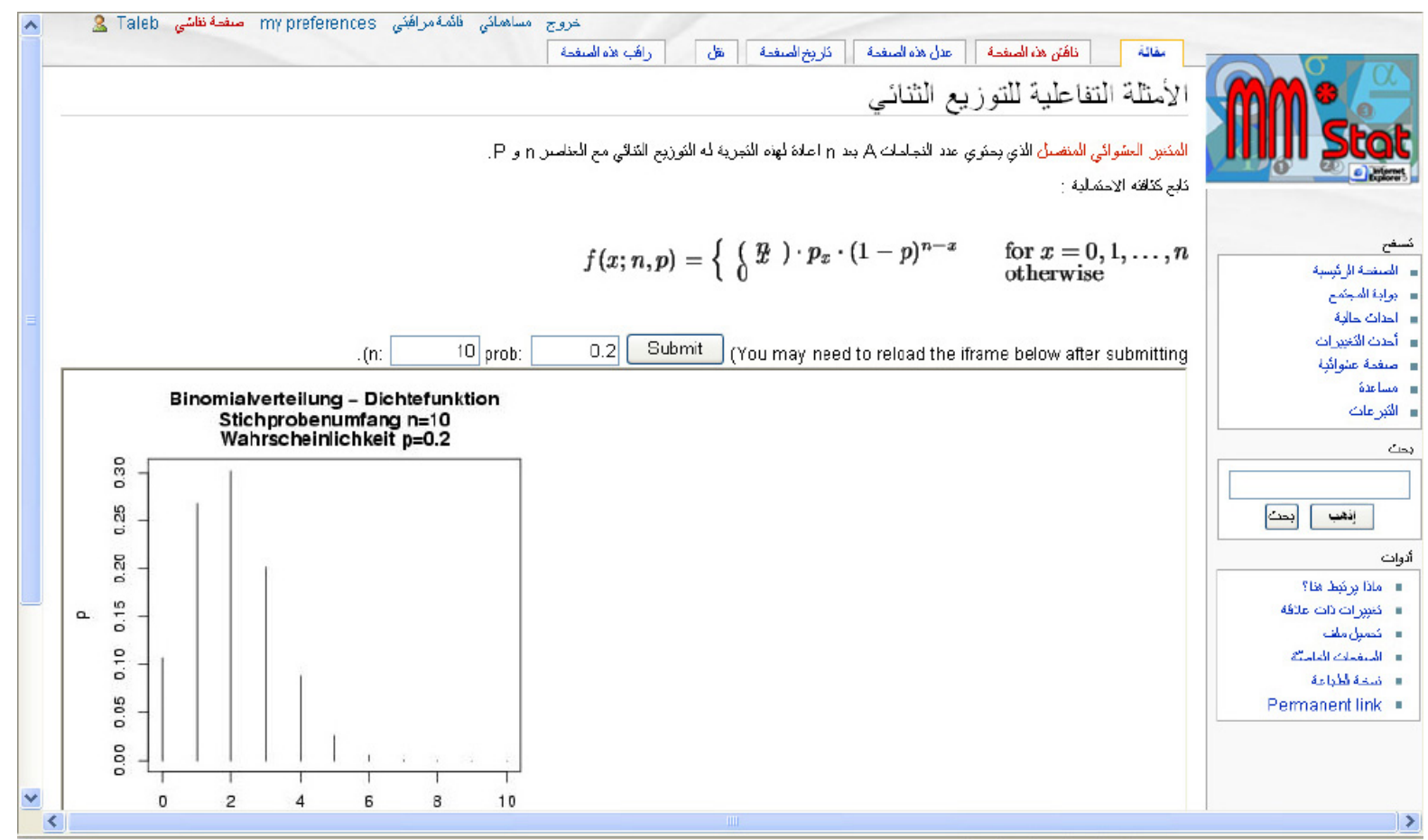

Figure 10: The interactive example for binomial distribution. 


\section{Conclusion}

Using E-learning/e-teaching tools to offer an effective learning of statistics is a necessity for students. There is the possibility of creating an e-learning system with Arabic MM*Stat through the application of Wiki technology. Since some of the specific characteristics we have discussed earlier for developing an Arabic platform already exist in the Wiki. We see that Rwiki is the solution for the interactive examples in Arabic $M M^{*}$ Stat. We hope that Arabic MM*Stat platform for e-learning of statistics will be a significant contributions to the Arab user as it clearly overcomes weaknesses in developing such electronic platforms in Arabic.

\section{References}

Ahmad, T., Härdle, W., Mungo, J., On the Difficulty to Design Arabic E-learning System in Statistics, COMPSTAT 2006 Proceedings, Roma, Italy (2006).

Al-Khatib, W., e-learning: Opportunities, Challenges and Future. Information and Computer Science Department. King Fahd University of Petroleum and Minerals, Dhahran, Saudi Arabia (2004) .

Al-Reeise, A., E-learning in Arab world, Oman 2004, http://www.elearning.edu.sa/forum/showthread.php?t=264

Dutta, S., El-Hage, C., Sabbagh, K., Tarazi, P., Challenges for Information and Communication Technology Development in the Arab World 2003.

Härdle, W., Klinke, S., Ziegenhagen, U., eLearning-A Critical Review, COMPSTAT 2006 Proceedings, Roma, Italy (2006).

Hoffmann, M., Arabic and Bidirectional Challenges for Translation and Software Development, Manager of Applications Engineering, ENLASO Corporation (2006). 
Klinke, S., Schmerbach, S., Troitschanskaia, O., Use of wikis in teaching. Statistics under one Umbrella, Bielefeld University, Germany (2007).

Lagally, K., ArabTeX : a System for Typesetting Arabic. User Manual Version 3.00, University Stuttgart (1993).

Lehmann, H., Client/Server Based Statistical Computing. Dissertation, HumboldtUniversität zu Berlin (2004).

Mungo, J., e-learning/e-teaching An Implementation and Evaluation of a Finance Introductory Course, Humboldt-Universität zu Berlin (2004).

http://edoc.hu-berlin.de/docviews/abstract.php?id=26937

Müller, M., Rönz, B., Ziegenhagen, U., The Multimedia Project MM*Stat for Teaching Statistics, In COMPSTAT. Proceedings in Computational Statistics, Physica Verlag (2000).

Maegaard, B., Choukri, K., Mokbel, C., Yaseen, M.,Language Technology for Arabic, NEMLAR, Center for Sprogteknolo gi. University of Copenhagen, July 2005.

http://www.quantlet.com/mdstat/products.html

http://pluto.wiwi.hu-berlin.de/mediawiki/index.php

http://www.linux.org.sy/node/51

http://www.serdal.com/articles/6/

http://www.sajed.org/news.php?ID=48

http://mars.wiwi.hu-berlin.de/mediawiki/slides/index.php/Main-Page 
http://www.r-project.org/about.html

http://en.wikipedia.org/wiki/R-programming-language

http://teachwiki.wiwi.hu-berlin.de

http://wiki.arabeyes.org

http://ar.wikipedia.org/wiki/. 


\section{SFB 649 Discussion Paper Series 2008}

For a complete list of Discussion Papers published by the SFB 649, please visit http://sfb649. wiwi. hu-berlin.de.

001 "Testing Monotonicity of Pricing Kernels" by Yuri Golubev, Wolfgang Härdle and Roman Timonfeev, J anuary 2008.

002 "Adaptive pointwise estimation in time-inhomogeneous time-series models" by Pavel Cizek, Wolfgang Härdle and Vladimir Spokoiny, January 2008.

003 "The Bayesian Additive Classification Tree Applied to Credit Risk Modelling" by Junni L. Zhang and Wolfgang Härdle, January 2008.

004 "Independent Component Analysis Via Copula Techniques" by Ray-Bing Chen, Meihui Guo, Wolfgang Härdle and Shih-Feng Huang, January 2008.

005 "The Default Risk of Firms Examined with Smooth Support Vector Machines" by Wolfgang Härdle, Yuh-Jye Lee, Dorothea Schäfer and Yi-Ren Yeh, January 2008.

006 "Value-at-Risk and Expected Shortfall when there is long range dependence" by Wolfgang Härdle and J ulius Mungo, Januray 2008.

007 "A Consistent Nonparametric Test for Causality in Quantile" by Kiho Jeong and Wolfgang Härdle, January 2008.

008 "Do Legal Standards Affect Ethical Concerns of Consumers?" by Dirk Engelmann and Dorothea Kübler, January 2008.

009 "Recursive Portfolio Selection with Decision Trees" by Anton Andriyashin, Wolfgang Härdle and Roman Timofeev, January 2008.

010 "Do Public Banks have a Competitive Advantage?" by Astrid Matthey, January 2008.

011 "Don't aim too high: the potential costs of high aspirations" by Astrid Matthey and Nadja Dwenger, J anuary 2008.

012 "Visualizing exploratory factor analysis models" by Sigbert Klinke and Cornelia Wagner, January 2008.

013 "House Prices and Replacement Cost: A Micro-Level Analysis" by Rainer Schulz and Axel Werwatz, January 2008.

014 "Support Vector Regression Based GARCH Model with Application to Forecasting Volatility of Financial Returns" by Shiyi Chen, Kiho Jeong and Wolfgang Härdle, January 2008.

015 "Structural Constant Conditional Correlation" by Enzo Weber, January 2008.

016 "Estimating Investment Equations in Imperfect Capital Markets" by Silke Hüttel, Oliver Mußhoff, Martin Odening and Nataliya Zinych, January 2008.

017 "Adaptive Forecasting of the EURIBOR Swap Term Structure" by Oliver Blaskowitz and Helmut Herwatz, January 2008.

018 "Solving, Estimating and Selecting Nonlinear Dynamic Models without the Curse of Dimensionality" by Viktor Winschel and Markus Krätzig, February 2008.

019 "The Accuracy of Long-term Real Estate Valuations" by Rainer Schulz, Markus Staiber, Martin Wersing and Axel Werwatz, February 2008.

020 "The Impact of International Outsourcing on Labour Market Dynamics in Germany" by Ronald Bachmann and Sebastian Braun, February 2008.

021 "Preferences for Collective versus Individualised Wage Setting" by Tito Boeri and Michael C. Burda, February 2008.

\section{SFB 649, Spandauer Straße 1, D-10178 Berlin} http:/ / sfb649.wiwi.hu-berlin.de

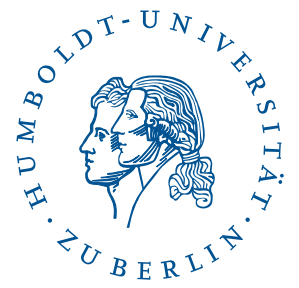


022 "Lumpy Labor Adjustment as a Propagation Mechanism of Business Cycles" by Fang Yao, February 2008.

023 "Family Management, Family Ownership and Downsizing: Evidence from S\&P 500 Firms" by Jörn Hendrich Block, February 2008.

024 "Skill Specific Unemployment with Imperfect Substitution of Skills" by Runli Xie, March 2008.

025 "Price Adjustment to News with Uncertain Precision" by Nikolaus Hautsch, Dieter Hess and Christoph Müller, March 2008.

026 "Information and Beliefs in a Repeated Normal-form Game" by Dietmar Fehr, Dorothea Kübler and David Danz, March 2008.

027 "The Stochastic Fluctuation of the Quantile Regression Curve" by Wolfgang Härdle and Song Song, March 2008.

028 "Are stewardship and valuation usefulness compatible or alternative objectives of financial accounting?" by J oachim Gassen, March 2008.

029 "Genetic Codes of Mergers, Post Merger Technology Evolution and Why Mergers Fail" by Alexander Cuntz, April 2008.

030 "Using R, LaTeX and Wiki for an Arabic e-learning platform" by Taleb Ahmad, Wolfgang Härdle, Sigbert Klinke and Shafeeqah Al Awadhi, April 2008. 